\title{
Pensar, dibujar, matar la ciudad: orden, planificación y competitividad en el urbanismo moderno**
}

\begin{abstract}
This paper offers a critical view on contemporary urban planning. With this aim, an itinerary starting with the process of rise and fall of rational-normative paradigm is traced, continuing with the birth of strategic planning, the discussion of urban reaches of competitive ethos, city marketing and urban cosmetic, finishing with an analysis of international rankings under the informational city paradigm. Using these elements, the paper ends with an analysis of current Santiago.
\end{abstract}

Keywords: Rational planning, competitiveness, urban marketing, Santiago de Chile.

\section{Resumen}

Este artículo ofrece una mirada crítica sobre la planificación urbana contemporánea. Para ello se traza un recorrido que arranca con el proceso de surgimiento y caída del paradigma racional-normativo, sigue con el nacimiento de la planificación estratégica, continúa con la discusión de los alcances urbanos del ethos competitivo, del city-marketing y de la cosmética urbana, y termina con un análisis de los rankings internacionales bajo el paradigma de la ciudad informacional. Utilizando esos elementos, el artículo cierra con un análisis del Santiago actual.

Palabras clave: planificación racional, competitividad, marketing urbano, Santiago de Chile. 


\section{Planificación racional-normativa: auge y caí- da de un modelo}

$\mathrm{D}$ esde hace siglos que Occidente viene comulgando con la idea de que existe un orden racional detrás de las cosas. El universo posee un sentido, y tal como lo afirmaron Platón o Leibniz, su orden guarda incluso una virtud $^{1}$. Ahora bien, es recién con la metodología que propone Bacon y con el monumental trabajo que realiza Newton que comienza a cobrarse conciencia de que esas leyes eternas, mecanicistas e inmutables podían ser conocidas: la ciencia moderna nace produciendo una fascinación tan magnética que, al menos en el imaginario popular, el siglo XVIII contempla una fe absoluta en que se lograría desterrar del mundo todo rastro de misterio. Cada fenómeno tenía su sentido y su lugar, y las excepciones que escapaban a la comprensión humana eran sólo nudos que no tardarían en ser desatados. El universo se había vuelto un lugar tan legible que Laplace llegó a plantear que, conociendo en un instante la posición y velocidad de todas las partículas, podríamos predecir el estado del universo en cualquier instante del tiempo, sea pasado, presente o futuro.

Un poco más tarde llegó Darwin, y con él un paradigma evolucionista que-si bien siguió el rumbo de la racionalidad-introdujo una novedad que marcó el punto de partida para buena parte de los procesos sociales del siglo XX: la comprensión del universo como un ente dinámico. Precisamente, es con el trabajo del naturalista inglés que comienza a descabezarse la inmutabilidad del mundo. La punta-de-lanza de su ataque fue la tesis de que las especies sobreviven en tanto son capaces de adaptarse a los cambios de su entorno. Ante esto, conceptos como estabilidad, permanencia o eternidad quedaron sobrepasados frente a las nuevas promesas que traían la evolución, el progreso y el desarrollo, todas ellas

\footnotetext{
* Sociólogo PUC, docente de la Escuela de Sociología de la Universidad Diego Portales; director Revista Bifurcaciones. Email: ricardogreene@gmail.com.

** Recibido el 4 de mayo de 2005, aprobado el 15 de julio de 2005.

1 "El universo [...] imagen sensible del dios inteligible, llegó a ser el mejor, el más bello y perfecto" (Platón, 1992) o "De todos los mundos posibles, Dios creó el mejor" (Leibniz, 1982)
}

nociones que anteponían lo temporal, el cambio y la transformación, a lo inmanente e inmutable. Lo rescatable de las propuestas de Darwin, para dar comienzo a este artículo, dice referencia con que el universo deja de ser entendido como un ente estático pero sigue manteniéndose rígido a leyes, lo que permite el nacimiento de un nuevo concepto, la planificación. Con él, la prometedora pero paralizante capacidad de leer el mundo se transforma en la expectante promesa de cambiar el mundo: los procesos no sólo podían ser radiografiados, sino también conducidos. Esta idea causó tal revuelo en su época que llevó a teóricos como Marx a plantearse el desafío de distinguir, en la historia, las leyes que determinan el devenir de las sociedades. La misma idea estructura La fundación, la obra más famosa del divulgador científico y escritor de ciencia-ficción Isaac Asimov, en la cual la psicohistoria ${ }^{2}$-una rama de las matemáticas que trata sobre las reacciones de conglomerados humanos ante determinados estímulos sociales- es capaz de predecir con exactitud el estado de la civilización diez mil años en el futuro, idea que aparece intermitentemente también en los escritos de "las tres B" de la ciencia ficción contemporánea: Benford, Bear y Brin. En la literatura de la época pueden encontrarse otros ejemplos de lo mismo, sea en el Frankestein de Shelley, en La isla del Dr. Moreau de Wells o en El Gólem de Meyrink.

Esta primera planificación fue una manera de entender el mundo que se caracterizó principalmente por su normatividad, ya que en tanto se quiere conducir un proceso se está seleccionando, en términos de su bondad, un escenario por sobre otros ${ }^{3}$. También destaca su racionalidad, ya que independiente de si el enfoque fuera comunista, capitalista o nacionalsocialista, los metadiscursos que intentaron planificar la sociedad durante el siglo XX se distin-

\footnotetext{
${ }^{2}$ Este concepto no guarda relación con aquella vertiente de la historiografía que también lleva por nombre psicohistoria, y que se preocupa por estudiar las estructuras inconscientes que mueven los procesos sociales. Agradezco a Pablo Páez por este comentario.

${ }^{3}$ Un contrapunto a esta idea puede leerse en la noción de atraso que condujo durante décadas el desarrollo de buena parte de Latinoamérica, ya que arranca precisamente del punto contrario: el recorrido es uno solo, y las diferencias entre los países se explican por cuán avanzados o retrasados se encuentran en dicho camino.
} 
guieron por situar al hombre como punto de partida, depositando una incuestionable confianza en el animal racional.

En este contexto, las ciudades eran un lunar de óxido en el rostro cromado de la modernidad. En una mentalidad que quería construirse enteramente desde sí misma, políticamente reelaborando sus estructuras y procedimientos, económicamente transformando sus formas de producción y culturalmente inaugurando un modo-de-vida propiamente urbano (Wirth, 2005; Simmel, 2005), las ciudades parecían ser lo único que no se adecuaba a este ritmo galopante de cambios y promesas. Asediadas por viejos y nuevos males, caóticas y desordenadas, sucias, malolientes y dueñas de una trama confusa más propia de tiempos bárbaros, las ciudades debían ser reformadas de manera urgente. El urbanismo nace en esta época precisamente con ese objetivo: encontrar, detrás de la maraña de caos ${ }^{4}$, un orden. El fundador de New Harmony, el socialista utópico Owen (1993), señalaba por esa época que "los grandes inventos modernos y el progreso continuo de las ciencias y de las artes técnicas y mecánicas [...] están destinados, tras haber causado bastantes sufrimientos, a destruir la pobreza, la inmoralidad y la miseria”, mientras que Considerant (1979), discípulo y continuador de la obra de Fourier, comulga con esta visión al señalar que "se acabó la confusión de todas las cosas; la odiosa mezcla de la ciudad y de la aldea civilizada; [...] la yuxtaposición monstruosa y desordenada de los habitáculos del hombre y de los animales, de las fábricas, de las cuadras, de los establos [...] El verbo de la creación ha resonado sobre el Caos, y se ha hecho el Orden”. Queda expuesto un urbanismo caracterizado por la firme creencia de que "el racionalismo, la ciencia y la técnica permitirán resolver todos los problemas relacionados a los hombres con el mundo y a los hombres entre sí" (Choay, 1976: 21).

Emblemática dentro de esta corriente fue la renovación integral del París decimonónico impulsada por Napoleón III y articulada por el Barón de Haussman. Esta buscó iluminar, bajo el foco del orden y siguiendo los preceptos de la fisiología higienista, un París de calles estrechas, contaminadas

${ }^{4}$ Véase, en especial, la obra de Charles Dickens y Arthur Conan Doyle, o más tardíamente la de Pío Baroja. y azotadas por las revueltas revolucionarias de 1830 y 1848 (Sennett, 1994; Grimberg, 1985)5 . El éxito de este último plan fue tal que sus postulados se replicaron pandémicamente por distintos puntos del orbe. Entre los muchos ejemplos que llaman la atención destacan el Plan de Barcelona, diseñado e implementado parcialmente por Idelfonso Cerdá, y la transformación de Viena a través de su RingStrasse ${ }^{6}$.

En Chile, las ideas de Haussman se plasmaron en un plan de renovación urbana que el intendente Benjamín Vicuña Mackenna, en una escala menor que las anteriores y guiado por una luz más elitista, impulsó en Santiago. Su objetivo fue regenerar las conductas y los hábitos de los ciudadanos, exiliando los vicios que se alojaban en los arrabales, esa "inmensa cloaca de infección y de vicio, de crimen y de peste, un verdadero potrero de la muerte» (Vicuña Mackenna, 1872). Para ello echó mano al orden, la belleza y la cultura, las que sembrarían la civilización dentro de la convivencia espacial y social de sus habitantes. La importancia radical que estos valores positivistas habían adquirido en el subcontinente puede leerse con claridad en los lemas nacionales que se inscribieron en varios escudos y banderas de los nacientes Estados latinoamericanos: en Brasil, por ejemplo, un "Orden y progreso" pretendía unir bajo la misma bandera un territorio gigante y dividido en razas, credos, lenguas y etnias; en Colombia, la " $\mathrm{Li}$ bertad y orden" llamaba a construir un ciudadano nuevo y emancipado, pero también racional y moderno, mientras que en Chile, el lema "Por la razón o la fuerza” era más duro en su premisa pero igualmente certero al trazar un camino de desarrollo que debía seguirse como si estuviera escrito a fuego. Esto da cuenta también, tal como nos recuerda Rama (2004), que la palabra escrita ha sido desde siempre una de las principales herramientas de planificación

\footnotetext{
${ }^{5}$ Este París que se intentó erradicar es el mismo París mítico de cafés y vida nocturna que se revela en los relatos de Baudelaire, Hugo, Balzac y Zola, y en las pinturas de Renoir, Degas, Pisarro, Manet y Monet.

${ }^{6}$ Mucho más adelante, en la década de 1930, los reformistas urbanos de Nueva York se propusieron reducir los procesos de desintegración social que anidaban fuertemente en los protoghettos de la época. Para ello se enfrentaron, con todas las armas disponibles, ante el mayor enemigo de todos: la calle, que con su vida urbana heterogénea y desbocada era caldo de cultivo para transformar a los vibrantes jóvenes en delincuentes (Sanders, 2003).
} 
urbana en Latinoamérica, y que por lo mismo, en emblemas, decretos, afiches, graffitis y banderas, se pueden rastrear con cierta facilidad las utopías urbanas de cada época.

A esta manera de entender la gestión urbana se le llamó planificación racional, una forma centralizada de dar forma a la ciudad y de conducir los procesos que en ella se iban sucediendo. Desde sus oficinas ministeriales, en las mesas de dibujo de los gobiernos locales, con el énfasis siempre puesto en el lápiz y la mirada siempre fija en la hoja en blanco, los arquitectos y protourbanistas se dedicaron a jugar con las ciudades como si pudieran armarlas y desarmarlas a su antojo. Lo que estaba construido carecía de importancia ya que lo relevante-lo glorioso- era que la imaginación corriera por los senderos de la razón, de la mano de la técnica, hacia la cumbre del progreso y del desarrollo ${ }^{7}$. Las tradiciones y costumbres, los recorridos y los ritos, las prácticas y las apropiaciones, lo simbólico y lo transitorio eran sólo escollos para esos objetivos, y el lápiz y la escuadra herramientas certeras para arrasar con todo ${ }^{8}$.

Lentamente, sin embargo, el mundo en general y la vida social en particular comenzaron a mostrarse mucho más complejas de lo que cualquier teoría podía abarcar. Heisenberg derrumbó en primera instancia la pretensión omniexplicativa al señalar, con su Principio de la Incertidumbre, que no puede conocerse al mismo tiempo la posición y la velocidad de una partícula, mientras que la teoría del caos, y en especial la famosa "sensibilidad a las condiciones iniciales” de Lorenz, dificultaron aún más esta tarea al introducir la contingencia dentro de las operaciones científicas. Y si bien la mecánica cuántica logró revivir temporalmente las pretensiones iluministas al incorporar la incertidumbre a la función de onda, el paradigma determinista no pudo nunca recuperarse de los sucesivos golpes que el siglo XX le proporcionó. Porque si ya el control racional de cualquier va-

\footnotetext{
${ }^{7}$ Característico dentro de esta corriente se encuentra el funcionalismo de la arquitectura moderna, con Le Corbusier como su figura por excelencia.

${ }^{8}$ Muchas críticas se han levantado a esta manera de entender el mundo, y más allá, de entender la arquitectura. Recomiendo especialmente la que construyeron los situacionistas y su vocero Debord en la convulsionada París de mediados del siglo XX.
}

riable-incluso de una sola- comienza a ser tarea desechada por la ciencia, el intento por controlar además sus cruces e interrelaciones se levantaba como una idea no sólo titánica, sino que fuera de toda realidad.

A la planificación normativa funcionalista se le puede criticar también su ingenuidad por plantear que toda necesidad podía ser satisfecha con la misma respuesta; por pensar que, siendo las necesidades de todos los hombres equivalentes (habitar, trabajar, entretenerse y circular), el diseño de una forma ideal bastaba para satisfacer a todos los hombres, en todas las naciones y sobre cualquier geografía. Ante esto, Niklas Luhmann levanta con ironía su concepto de "equivalentes funcionales", proponiendo que una necesidad podía ser satisfecha con múltiples alternativas, todas ellas equivalentes entre sî ${ }^{\hat{~}}$. Esto se relaciona con una visión de la complejidad que llama a abandonar la causalidad, ya que el engranaje entre causas y efectos que establece un observador depende siempre de los intereses con los que ordena el objeto, o en la medida en que confiere importancia a determinados efectos. El mundo viene así definido como la infinitud de las posibles relaciones entre causas y efectos que en sí mismas son axiológicamente neutrales, pero que en virtud de la preferencia de los valores de un observador pueden adquirir una estructura de relevancia.

A raíz de estas y otras interpretaciones, la realidad del mundo se fue mostrando, de lo micro a lo macro, racionalmente indomable ${ }^{10}$. En Latinoamérica este fenómeno puede leerse, por ejemplo, en el hecho de que durante los sesenta un Estado keynesiano empecinado con el desarrollo y maravillado por las promesas cepalinas impulsó una acelerada industrialización que no guardaba relación alguna con la realidad de las economías locales. Lejos

\footnotetext{
${ }^{9}$ Casi al final de su vida, instigado por Torres Navarrete a hablar de la muerte de su esposa y de su mejor amigo, Luhmann confiesa que la noción de los equivalentes funcionales ha perdido interés para él.

${ }^{10}$ Lo macro se pudo ver por ejemplo en la Unión Soviética, donde se hizo evidente (lo sabemos ahora) la imposibilidad de regular en su totalidad el mercado; lo micro, en lo que De Certeau (1984) llamó la microfísica de la resistencia, aquellas prácticas mediante las cuales las personas intentan reapropiar los espacios públicos en tanto usos y condiciones.
} 
de producir crecimiento y bienestar, las políticas aplicadas dieron nacimiento a cordones de pobreza que sitiaron y empobrecieron buena parte de las grandes ciudades del subcontinente. Ese caso pone en evidencia un racionalismo que exacerba la causalidad, ya que supone que siempre, bajo cualquier circunstancia, una determinada causa (i.e. la industrialización) producirá determinados efectos (i.e. el progreso). Con todo, se fue revelando el agotamiento de un modelo que, basado en el keynesionismo económico y fuente de la que había bebido el Estado de Bienestar durante décadas, parecía no sólo no ofrecer solución alguna a los problemas que se apilaban en las ciudades, sino incluso hundirlos en un hoyo más profundo.

Ahora bien, pese a la disconformidad que fue generando el modelo racionalista de planificación urbana, y a lo difícil que se hacía adscribirse teóricamente a él, esta manera de pensar y dibujar la ciudad siguió siendo la manera en que los urbanistas condujeron -o intentaron conducir- los procesos urbanos. La incertidumbre y la "irracionalidad del racionalismo" podían ser efectivamente más ciertas, pero también más inmanejables. Porque, ¡cómo se ordena una ciudad cuando no es posible establecer causalidades? ¿Cómo se proponen modelos cuando las necesidades pueden satisfacerse de infinitas maneras? ¿Cómo se planifica una ciudad cuando se está consciente de la diversidad de visiones sobre lo que ella debe ser? Estas preguntas desestabilizaron el urbanismo y quedaron sin respuesta durante años, hasta que surgieron nuevos paradigmas de planificación que intentaron incorporar estas nuevas condiciones. Así, luego de años provocando fervor y coincidiendo con la crisis del petróleo de los setentas, la planificación racional-normativa dejó de ser ampliamente defendida y surgieron modelos alternativos que exacerbaron el desmantelamiento del Estado y favorecieron la participación civil en la conducción de los procesos.

\section{El repliegue del Estado y el paréntesis del neoliberalismo}

En un escenario "donde la inoperancia de la planificación normativa racionalista ya era evidente, $y$ la palabra planificación rápidamente había comen- zado a perder su atractivo y su poder de convocatoria” (De Mattos, 2004), urgía la necesidad de encontrar -incluso crear- un nuevo modelo de desarrollo. Para Castells (1987), lo que se buscó fue una sustitución de los mecanismos históricamente inaplicables del modelo por otros capaces de asegurar "la generación de excedente, la elevación de las ganancias, el desarrollo de mercados en forma equivalente, y la regulación del ciclo económico y las condiciones generales de producción”.

El modelo que daba en ese entonces apariencia de responder a las exigencias planteadas era, para muchos, el capitalismo de cuño neoliberal, ya adoptado con relativo éxito en lugares como el Asia-Pacífico o Chile. Su principal promesa y aparente virtud era su capacidad de regular el mercado -y de ahí la vida social toda, tributaria inapelable de las variables económicas- sin los ingentes esfuerzos y gastos que exigía el Estado centralizado. Con la adopción de este modelo, el bolígrafo del planificador y la imagen-objetivo de la ciudad fueron dando paso a pautas de desarrollo que se encontraban sólo a merced de las curvas de oferta y demanda.

La propuesta, sin embargo, no hizo mucho por solucionar el problema. En Chile, por ejemplo, a sólo cinco años de su promulgación, la política radical de liberalización de los mercados de suelo (DS420/79) evidenciaba tantos y tan serios problemas que tuvo que ser reelaborada casi por completo. El mercado de la ciudad -los mercados de suelo- demostraba ser mucho más complejo que el resto de los mercados, y la tierra un bien mucho más particular que el resto de los bienes, competitivos e intercambiables (Sabatini, 2000). Los efectos perversos de esta política desbocada, como el aumento en los precios de suelo, no tardaron en levantar polvo y en exigir un nuevo reescalamiento del Estado, esta vez devolviéndole parte de sus facultades fiscalizadoras y de conducción de procesos sociales. Con ello, y pese a que todavía pueden rastrearse trazos de esta política liberalizadora en la manera de conducir los procesos urbanos chilenos, se ha vuelto bastante compartida la noción de que la iniciativa privada debe estar sujeta a la planificación estatal y que el derecho de propiedad debe restringirse cuando contrasta con el bien común. 


\section{Planificación estratégica: el reescalamiento de la incertidumbre}

Tal como postulan Borja y Castells (1997), el modelo neoliberal fue reelaborado, generándose una dialéctica "entre revolución tecnológica y estructura social". Al pulso hasta entonces monocorde de la economía se sumaron otras voces, reconstituyéndose con ello el coro polifónico de la vida social. Los planes urbanos comenzaron a implementar un tipo de planificación adaptativa que recogía la contingencia del mundo mediante un sistema de normas dinámicas y adecuables al movimiento del sistema urbano. Este cambio fue radical en cuanto a la manera de hacer ciudad, ya que la mirada dejó de estar puesta en el largo plazo para enfocarse en objetivos más inmediatos.

En este esquema, una de las ideas centrales fue que tanto los derechos como las responsabilidades se encontraran calculadamente distribuidas entre la esfera pública y la privada (PPP). El nuevo rol del Estado, para Porter (1998), se centró "primero que nada y ante todo, [en] preocuparse por crear un ambiente que mantenga y genere productividad", opinión que comparte la OECD (1997) al señalar que "el rol del gobierno está indudablemente pasando de la directa provisión a la habilitación" ${ }^{\prime 11}$ (1997). Es un Estado que abandona sus funciones tradicionales para transformarse en un facilitador, un ente que genera desarrollo local a partir de la coordinación de instancias de trabajo y del fortalecimiento de mecanismos participativos en la toma de decisiones; un Estado ante todo que se desmembra para potenciar procesos de empoderamiento y de governanza local. A esta nueva-pero neoclásica- modalidad de regular y conducir los procesos urbanos se le llamó planificación estratégica.

La planificación estratégica, como todos los modelos que hemos revisado hasta ahora, presenta también defectos. La primera crítica que puede hacérsele radica en su naturaleza misma: al trabajar sólo sobre piezas reducidas de ciudad, al operar únicamente con plazos inmediatos e instantáneos, sus efectos distan mucho de ser relevantes. Un breve recorrido por algunos de los más renombrados proyectos de renovación urbana estratégica del último tiempo-

\footnotetext{
11 Traducción propia.
}

como Cannary Warf en Londres, Puerto Madero en Buenos Aires o el Pier 17 de Nueva York- nos da una respuesta única: los millones de dólares invertidos y el esfuerzo de años y de personas por renovar zonas deterioradas y en desuso se traducen aparentemente sólo en lugares diseñados por y para las elites, en espacios plásticos y vacíos, subutilizados y ventajosos sólo para ilustrar panfletos turísticos; fracasados, en definitiva, en su intento por recrear-de manera controlada y calculada- el caos, vértigo y heterogeneidad que poseen los ejes urbanos tradicionales. McMorrough (2001) le llama a esto "el segundo triunfo del suburbio sobre la ciudad", haciendo alusión a que, habiendo dañado primeramente a la ciudad tradicional mediante el vaciamiento de sus centros históricos, el suburbio le inflige una segunda laceración cuando los suburbanitas vuelven a la ciudad y la reconstruyen bajo las lecciones aprendidas en la periferia, especialmente en el mall. Los espacios públicos remodelados por la planificación estratégica estarían, bajo esa lógica, intentando replicar social y morfológicamente las relaciones que se despliegan en los shopping centers, caracterizadas por la jerarquía, el miedo al extraño y la simulación.

Otra falencia de la planificación estratégica reside en el nuevo e importante rol que se les asigna a los gobiernos locales luego de la retracción del Estado. El problema radicó en que las políticas descentralizadoras lograron efectivamente asignarles a dichos gobiernos una serie importante de responsabilidades, pero éstas no se vieron acompañadas del financiamiento, capacitación, mecanismos institucionales y cobertura legal necesarias para ejecutar de manera eficiente sus tareas. Desprovistos del patrocinio directo e incluso indirecto de un Estado benefactor, sobrepasados en deberes y con sus arcas quebradas, los municipios se vieron abruptamente lanzados a la arena de un coliseo moderno -el espacio mundial de acumulación-, donde tanto comunas como ciudades, regiones y países compiten por las migajas del dinero transnacional. Esta razón, sumada a procesos más complejos que se comentarán más adelante, hicieron de la competitividad una especie de panacea que se deshizo en boca de todos, un analgésico que comenzaron a exigir los convalecientes territorios a los médicos de hoy: consultores, lobbystas y políticos capaces de atraer las inversiones no sólo mediante el mejoramiento real de los índices, sino tam- 
bién a través de intrincadas campañas de marketing que revalorizan los territorios, a la vez que los ponen en la mira de agentes internacionales. La novedad de este punto no radica en el hecho de que las ciudades compitan, cosa que sin duda hacen desde siempre, sino en que a partir de los ochentas la competencia comienza por primera vez, a partir de un sólido marco teórico, a hacerse bajo la aplicación consciente y rigurosa de herramientas de marketing (Ashworth y Voogd, en Van den Berg y Braun, 1999).

Con el repliegue del Estado a funciones fiscalizadoras y promotoras termina este breve vuelo sobre la historia de la gestión y planificación urbanas. Es importante señalar que, con el objetivo de compeler a países con realidades e historias muy diversas bajo la fuerza de un mismo recorrido, el análisis se ha realizado con una visión de gran escala, por lo que se comprende que bajo miradas locales y particulares el análisis deba complejizarse, entendiendo que las relaciones entre transformaciones territoriales y paradigmas sociales y científicos deben tomar en consideración la capacidad que tienen los actores (y la contingencia) para conducir o resistir los cambios del discurso dominante (De Certeau, 1984; Foucault, 1992). Puede decirse que cada ciudad tiene un espíritu, y que tanto los ciudadanos como quienes manejan las políticas urbanas -cuando las hay- deben y suelen mostrar preocupación por ajustar los dictámenes de la economía transnacional a la naturaleza de cada complejo urbano.

Ahora bien, la nueva modalidad bajo la cual se ha articulado el último tiempo la competencia urbana debe necesariamente acompañarse de una discusión sobre si las ciudades realmente compiten, y si lo hacen, sobre la base de qué factores.

\section{Competitividad urbana: definición y complejización del concepto}

Las ciudades compiten. Esa afirmación ha sido fuente de intensas discusiones desde el arribo del nuevo contexto internacional. Las posiciones contrapuestas quedan bien reflejadas en los trabajos de Krugman (1996) y de Porter (1990 y 1998). Para el primero, no son las ciudades como tales quienes compiten, sino que éstas son el locus o territorio desde el cual las firmas compiten. Las ciudades son sólo una condición de posibilidad, un escenario desde el cual se articula la competencia de actores sociales. Porter, por su parte, arranca de la idea de que, anclado en los procesos de globalización e informatización de la sociedad, ha surgido un sistema económico único o una economía mundial, en la que el capital fluye de un lugar al otro en búsqueda de mejores rentabilidades. Este escenario ha llevado a las empresas a fragmentar sus operaciones con el objetivo de facilitar su movilidad por las distintas coordenadas del globo. Pero no hacia cualquier lugar. Al contrario de lo que ocurría tradicionalmente, a partir de los setentas ya no son los territorios nacionales los que constituyen la "base geográfica para el desarrollo industrial capitalista" (Brenner, 2003), sino que ahora son las ciudades, cuyas particularidades las vuelven altamente atractivas para acoger los volátiles capitales. Para Veltz (1996), precisamente, la metropolización de la economía "se afirma como la tendencia principal del decenio", mientras que para Sassen (1991) "las nuevas tecnologías de la comunicación favorecen la deslocalización de las actividades de producción; pero, en la medida en que esta dispersión se produce en un sistema económico que se caracteriza por una concentración siempre mayor del control, de la propiedad y de la apropiación de la ganancia, las nuevas tecnologías dan también una importancia determinante a las funciones centrales de dirección de las grandes firmas mundiales". Castells y Mollenkopf retoman esta y otras ideas de Sassen, para señalar que hoy la gestión del capital financiero mundial se encuentra organizada en corporaciones bancarias y empresas bursátiles, las que tienden a centralizar y concentrar sus operaciones produciendo, entre otras cosas, la dualización de las ciudades (precisado en Trujeque, 2000).

Bajo esta última mirada se desamarran varios de los conceptos sobre los que se asienta parte de la teoría postmoderna, tales como el descentramiento de las ciudades y la aterritorialización de las relaciones sociales. Construcciones teóricas como el desanclaje, que propone que las relaciones sociales se han desarraigado de los contextos de experiencia espacio-temporal inmediata y de la interacción personal, para reconstruir acciones y relaciones a distan- 
cia $^{12}$ (Giddens, 1993), comienzan a ser confrontados por estudios que reivindican la importancia y necesidad de las relaciones cara-a-cara, como por ejemplo los desarrollados por el colectivo francés "Dynamiques de proximité" (Gilly y Torre, 2000). Con ello, la globalización deja lentamente de ser entendida como algo enteramente virtual o virtualizante, para empezar a comprenderse como un fenómeno complejo que requiere, para operar, de centros de comandos materiales con características netamente urbanas.

Una visión distinta sobre el tema ha sido articulada por los economistas del crecimiento endógeno. En contraste con la visión neoclásica de crecimiento, que tiene en Solow a su autor cumbre, este modelo sostiene que el progreso de una economía está dado por aquellos factores inherentes al sistema. Entre las muchas variables relevantes a considerar, los teóricos del crecimiento endógeno ponen por primera vez en un lugar prioritario a la innovación ${ }^{13}$, lo que propone un cambio de mentalidad que intenta pasar de lo material a lo intelectual, de lo escaso a lo ilimitado, de lo que se gasta a lo que permanece, de lo excluyente a lo plástico, de lo desfasado a lo simultáneo, de lo tangible a lo intangible, del capital, el acero, las fábricas y el petróleo a los avances tecnológicos, la investigación y el desarrollo. Romer llama a este proceso la revolución del soft (Rodrigues, 2001). En este cambiante escenario, son nuevamente las ciudades las que tienen reservado un puesto de privilegio. Porque al contrario de los bienes activos, en su mayoría anclados inseparablemente a lugares específicos, los activos intangibles pueden moverse con mucha mayor libertad por el mundo, buscando condiciones que los potencien y maximicen. $\mathrm{Y}$ esos atributos no se encuentran tanto en los territorios nacionales sino en las ciudades, las que, con hetero-

${ }^{12}$ En una palabra: virtuales. Pero dado que la virtualidad ha estado presente desde siempre en toda sociedad desde el rudimentario poder de los antiguos reyes y emperadores que se expandía y mantenía por el mundo sin su presencia directa hasta la hegemonía del cristianismo en la Edad Media-, lo novedoso de la modernidad es la autorreflexión que produce sobre ella.

${ }^{13}$ Los avances en tecnología, en este contexto, no serían variables que existen fuera del sistema económico, sino más bien "un subproducto de la actividad económica, o bien como fruto de una actividad (I+D) guiada por incentivos económicos individuales" (Conesa, 2005). geneidad de funciones, diversidad poblacional, densidad y plasticidad, se levantan como los lugares y la escala más adecuada para soportar y potenciar la creatividad. Por lo mismo, muchos gobiernos metropolitanos y nacionales se han volcado, en los últimos veinte años, a atraer migrantes con altas calificaciones, ya no sólo seduciéndolos desde países con menores ingresos sino ahora también disputándoselos a otros países desarrollados. Ejemplos de esto hay muchos y de distinto orden: en Estados Unidos, a comienzos de los noventa, se corrigió la ley migratoria para ampliar las cuotas de inmigrantes calificados; en Japón, por la misma época, el gobierno comenzó a tomar medidas para recobrar parte del alto número de japoneses calificados que se encontraban trabajando fuera del país; en Alemania, a mediados de los noventa, se implementó el programa "Green Card" para reclutar trabajadores especializados y atraer estudiantes calificados; y en el Reino Unido, se lanzó en 1999 una campaña para facilitar el ingreso de estudiantes extranjeros en universidades locales, otorgando becas y reduciendo las rígidas exigencias para obtener visa.

Por último, hay autores como Begg (1999), quienes se adscriben a la facción de competitividad urbana, pero ponen el acento en lo que puede y debe hacer la autoridad para favorecer la atractividad de una ciudad: "Si bien muchos de los factores que influencian el actuar urbano dependen de movimientos económicos nacionales e incluso transnacionales", afirma, "hay muchos aspectos de políticas que una ciudad sí puede controlar, y que tienen relación con su competitividad"14. Su aporte dice relación con que las ciudades no deben sólo preocuparse por competir sino también por desarrollar procesos de cooperación y de intercambio -incluso con quienes compiten-, tanto internamente como a nivel regional, nacional e internacional. Para autores como Cabrero et al. (2003), esta cooperación se relaciona con que "los actores gubernamentales, económicos, sociales y políticos del ámbito local que actúan, principalmente, de manera asociada o en redes sobre determinado territorio, pueden cumplir un papel importante para movilizar o atraer la inversión, los servicios avanzados y la mano de obra calificada, obtener fondos públicos, propiciar el de-

\footnotetext{
${ }^{14}$ Traducción propia.
} 
sarrollo de sectores de alta tecnología, el turismo, eventos internacionales $\mathrm{u}$ otras actividades productivas generadoras de riqueza, empleo y mejores condiciones de vida para quienes habitan las ciudades". La autoridad urbana, como puede apreciarse en las palabras de Cabrero, se debe hoy limitar a cumplir un papel gestionador y de promoción, lo que revela una posición que retrae lo público y mercantiliza a la ciudad.

La venta de las ciudades en el mercado internacional es criticada por muchos, pero también reconocida como necesaria y positiva por otros. Dematteis (1998/99), por ejemplo, llega a afirmar que una ciudad sobrevive sólo en tanto es y permanece atractiva: "Si no es un nodo, no se es nada" señala, aludiendo a que si un territorio no es capaz de atraer inversiones ni personas, en la era de los flujos globales, entonces ese territorio simplemente no es una ciudad. Este enfoque es central para entender el fenómeno de la competitividad y para justificar la importancia de los rankings internacionales.

\section{Promoción y venta de la ciudad moderna}

Como ya se ha dicho, las ciudades han competido desde siempre. Lo novedoso es que hoy lo hagan utilizando conscientemente herramientas del marketing $g^{15}$. Las ciudades son preparadas, cosmetizadas y ofrecidas por asesores peritos en las leyes del mercado, quienes las ofrecen de la misma manera en que promocionarían un par de zapatos o un automóvil de última línea ${ }^{16}$. Su objetivo es "proyectar una imagen de ciudad dinámica e innovadora, estimulante y creativa, capaz de competir con éxito por la atrac-

15 No sólo las ciudades están operando bajo esta lógica, sino que también los países. En Chile, por ejemplo, el gobierno lleva ya un par de años declarando la importancia de consolidar la "Marca Chile". A modo de ejemplo, citaré las palabras que el Alto Representante de Chile en la reunión APEC 2004, Ricardo Lagos Weber, al inaugurar la sesión dijo: "El país tiene, a lo largo del año APEC, la posibilidad de poner geografía y rostro a la marca Chile" ( h t t p : / / w w w. a p e c 20004 . c $1 /$ not_hist_det.asp?Id=65\&idioma $=$ esp).

16 Para un análisis más profundo de este fenómeno véase Vainer (2000). ción de inversiones productivas y funciones direccionales" (Rodríguez, Moulaert y Swingedouw, 2001). Así, si bien para algunos autores las ciudades compiten de manera distinta que las empresas (Lever, 1999), para los creadores del urbanismo empresarial esto no es tan así.

Detrás de este accionar hay un supuesto de fuerza que dice relación con que las ciudades no son sólo la suma de sus componentes tangibles, sino también -y más importante aún- el agregado de su contraparte simbólica e imaginaria. Detrás de cada ciudad material hay cientos de ciudades invisibles, discursivas y escurridizas, un conjunto inarticulado de imágenes e ideas tanto o más complejas que la propia ciudad física. La imagen que una ciudad construye de sí misma es recreada continuamente, y puede ser pieza fundamental para su óptima inserción al mercado mundial. Sea obviando o aprovechándose de una imagen compartida de ciudad, los promotores inmobiliarios vuelven "homogéneos y homogeneizantes" (Torres, 1996) ciertos discursos sobre los espacios urbanos o piezas específicas de ciudad, a tal nivel que pronto se vuelve prácticamente ineludible-tanto para extranjeros como para nativos- hablar de Valparaíso como "la perla del Pacífico", de París como "la ciudad luz" y de Nueva York como "la ciudad que nunca duerme"; o disociar Río de Janeiro de mujeres y playas; Praga de música clásica y arquitectura deslumbrante y Buenos Aires de lectura, parques y vida nocturna. Ejemplos de la aplicación consciente y rigurosa de esta herramienta pueden verse en los proyectos de renovación españoles de Barcelona en 1992, que logró cargar simbólicamente al puerto catalán de conceptos atractivos como multiculturalidad y heterogeneidad, y luego más tarde en el de Bilbao a fines del milenio, que logró que el nombre la ciudad comenzara a significar otras cosas que puerto industrial y terrorismo independentista. Ambos casos han pasado a ser emblemáticos en cuanto estrategias de marketing exitosas que, tal como en cualquier otro mercado, le entregaron un valor agregado al producto ofrecido.

Al menos dos grandes reparos pueden hacérsele a ese enfoque. El primero dice relación con que, pese a la importancia que ha adquirido en las últimas décadas el marketing urbano, no deja de ser sólo una construcción cosmética que por sí misma no es capaz 
de lograr resultados sostenibles a mediano ni a largo plazo. Y no sólo a nivel de inversiones, sino que -y más importante aún- en mejoras reales a la calidad de vida de sus habitantes. Según Van den Berg y Braun (1999), el marketing debe ser parte de un proyecto integral que incluya una organización administrativa, redes estratégicas, liderazgo, visión y estrategia, condiciones espacio-económicas, soporte político y el apoyo de la comunidad. Esta última variable, de hecho, ha sido fundamental para determinar el éxito o fracaso de muchos proyectos de renovación urbana. El éxito puede verse, por ejemplo, en los casos de San Quentin de Yvelines, en Francia, y de Lowry, en Denver; el fracaso, como contrapunto, se puede leer con claridad en el caso de los Docklands (Londres), cuya lenta y costosa consolidación puede atribuirse en buena medida a la incapacidad de la Corporación de Desarrollo de los Docklands de Londres (LDDC) para involucrar de manera participativa a la comunidad en el diseño, implementación y continuidad del proyecto. En ese sentido, si en Barcelona o en Bilbao los proyectos de marketing fueron exitosos en sus objetivos fundamentales, pese a todo lo discutibles que hayan podido ser en otras dimensiones, fue porque se encontraban insertos en un plan integral de desarrollo del cual este marketing era sólo una voz; de otra manera hubieran sido sólo, parafraseando a Hamlet, a king of shreads and patches, una especie de analgésico de corto alcance que produce alivio momentáneo pero se diluye sin dejar más rastro que un dolor de cabeza.

El segundo punto cuestionable dice relación con que el marketing urbano opera comunicando selecciones elaboradas de ciertas piezas de ciudad o de individuos y sus relaciones dentro de ella. Y como toda luz genera sombras, cada vez que algo se pone en el foco se hace a costa de un conjunto de cosas que quedan sin distinguir, como un opaco fondo incuestionado ${ }^{17}$. Como bien señala Hidalgo, "la noción misma de competitividad supone la ocultación de las desigualdades sociales, toda vez que éstas se constituyen en vectores de desvalorización de una

${ }^{17}$ A partir de esto surgen preguntas legítimas en relación a los mecanismos de poder y los medios de comunicación, quienes tienen la capacidad de poner ciertos temas en discusión por sobre otros. Para seguir esta discusión véase especialmente el concepto de Agenda Setting en McCombs y Shaw (1973). ciudad; en este sentido, se debiese apuntar menos a dilucidar cómo las desigualdades sociales se transforman en un factor que juega en contra de la competitividad, que a evidenciar los mecanismos en virtud de los cuales determinadas áreas urbanas son favorecidas en desmedro de otras, sistemáticamente excluidas de los circuitos de inversión pública y privada" (en De Mattos et al., 2004). La duda natural que surge de esta posición, por tanto, es que si bien en un comienzo eran los países los que competían, y luego más bien las ciudades, quizás ahora habría que cerrar un poco más el foco y reconocer que sólo ciertas piezas de ciudad son las que compiten, en tanto otras no sólo quedan atrasadas sino que, más grave aun, son sistemáticamente excluidas y ocultadas a ojos nacionales y extranjeros. Una confirmación práctica y didáctica de este hecho puede obtenerse al desdoblar el plano turístico de cualquier ciudad. Se comprobará con facilidad que la ciudad real -material- ha sido comprimida y reducida sólo a un par de barrios atractivos al mercado y a los turistas. El resto, simplemente no existe.

\section{Rankings: las ciudades compiten}

Ahora bien, habiendo establecido el estado de la discusión puede ahora avanzarse sobre otro punto que también ha sido fuente de intensos debates, a saber: la identificación de aquellas variables específicas que hacen de la ciudad un producto más apetecible en el mercado internacional.

Una vez que a fines de los ochenta comienzan a utilizarse herramientas del marketing para promocionar las ciudades, comienzan también a desarrollarse otras herramientas, esta vez analíticas, para medir y comparar a las ciudades en tanto la atractividad que ofrecen a las empresas. Los primeros de estos rankings, desarrollados por revistas especializadas en primera instancia y luego por poderosas consultoras transnacionales, se caracterizaron por presentar un fuerte sesgo economicista, suponiéndose que basta con controlar los factores económicos (crecimiento económico, aumento del empleo, aumento del ingreso per cápita, etc.) para conducir el desarrollo y atraer las inversiones. Entre los autores más significativos de este enfoque se encuentra Michael Porter, quien si bien toma en consideración factores como la institucionalidad y la educación, puede decirse que 
el centro de su análisis se localiza en las variables económicas. En su análisis, los determinantes de la competitividad son cuatro: las condiciones de factores de producción, las condiciones de demanda interna, las industrias relacionadas y de apoyo, la estrategia, estructura y competencia interna de las empresas, y por último "otras variables del sistema", donde recién comparecen fenómenos como las epidemias, sucesos políticos externos o guerras (Porter, 1990), que si bien no pertenecen al ámbito económico, están consideradas sólo en tanto son capaces de afectarlo.

Otros rankings que operan bajo la misma lógica son el del International Institute for Management Development (IMD), que prepara sus informes de competitividad basado en factores como la fortaleza de la economía nacional, la internacionalización, el estado del gobierno, la actividad financiera, el nivel de las infraestructuras, el tipo de administración, la inversión en ciencia y tecnología y los recursos humanos (citado en De Mattos et al., 2004); el de Sachs y McArtur (2001), que toma en consideración variables agrupables en tres ejes: ambiente macroeconómico, calidad de las instituciones públicas y desarrollo tecnológico; el de Webster y Muller (2000), para quienes la competitividad urbana está determinada por las variables económicas, las territoriales, las institucionales y las que dicen relación con los recursos humanos; y el ranking estadounidense de Best Cities, que busca orientar la inversión de las empresas en base a variables como la actividad empresarial, el crecimiento de las pequeñas empresas, el crecimiento económico y el riesgo.

Un punto a destacar de estos rankings de competitividad es que hacen oídos sordos al fenómeno del marketing urbano. La imagen de la ciudad, para ellos, no es un punto a considerar, y son sólo las variables estructurales las decisivas para determinar la localización de las empresas en el mercado único mundial.

\subsection{Complejización de los rankings de competitividad: la inclusión de la calidad de vida}

Al igual que el camino recorrido por la planificación de las ciudades, los rankings urbanos arrancaron de una visión centrada en lo económico que luego se abrió para incorporar otras variables del sistema social. Con esto se reconoció que lo atractivo de una ciudad -para las empresas y para las personasno descansa sólo en variables económicas, sino que es construido también desde las sociales y medioambientales. A esto colaboró que los noventa se hayan definido por un zeitgeist que poseía dos características imbricadas: en primer lugar, una revalorización del entorno y una regeneración de los movimientos ecologistas, y en segundo lugar, el arribo de una generación que comienza a sacudirse de aquellas promesas inconclusas del mercado que habían hipnotizado a los jóvenes yuppies de los ochentas. La preocupación prioritaria y los ojos de muchos se vuelven a la calidad de vida urbana, entendida como la preocupación por el bien común a la vez que el resguardo por el medioambiente. El Banco Mundial, de hecho, define a la competitividad como "la condición que le permite a una sociedad, en un contexto de economía de mercado, producir y prestar bienes y servicios que cumplan con los requisitos de los mercados internacionales, mientras simultáneamente expande el estándar de vida de la gente" 18 . Esta definición coincide con la propuesta de Sobrino (1999), para quien la competitividad es "el incremento en la eficiencia económica local y el aumento en las condiciones de vida de la población". Lever (1999), por su parte, afirma que "las ciudades competitivas son aquellas capaces de conciliar calidad de vida con altos niveles de vida, aunque éstos no son necesariamente compatibles". En una línea más crítica, Krugman (1996) reclama que el énfasis no debe estar puesto en el crecimiento económico por sí solo, sino en su relación con la calidad de vida: "El fundamento de la competitividad es la productividad, pero su incidencia en la calidad de vida se da a partir del aumento en los salarios reales de la población”. Alburquerque (1995) también ataca la visión economicista, al plantear que "el objetivo del desarrollo regional no depende de la imprecisa noción de competitividad, sino de la productividad con que se empleen los recursos humanos, financieros, físicos, tecnológicos para alcanzar un alto y creciente nivel de vida para sus habitantes". Como puede verse, son muchos quienes han planteado que la competitividad no debe entenderse nunca como un

${ }^{18}$ Véase www.zonacomercial.net/ediciones/Consultores/ cdpc.html. 
fin sino como un medio, y que de nada sirve que una ciudad sea capaz de atraer empresas y capital si con ello no es capaz de mejorar la calidad de vida de sus habitantes.

Entre los rankings de competitividad que han incluido variables relacionadas con la calidad de vida se encuentra el Best Cities in Asia, que considera el desempleo, los gastos en educación, el número de camas en los hospitales, la calidad del medio ambiente, la inflación, la criminalidad, los medios de comunicación (Internet, teléfonos, móviles, etc.), y la esperanza de vida. Interesante, en esta línea, es también la propuesta de Cabrero et al. (2003), para quienes la competitividad se compone de factores agrupables en cuatro dimensiones: la sociodemográfica, que refiere a los rasgos poblacionales que determinan diferenciales en la competitividad; la urbano-espacial, compuesta por las características de la infraestructura urbana, de la calidad de los servicios urbanos, del equipamiento en educación, salud, medio ambiente, parques industriales y telecomunicaciones; la institucional, integrada por las propiedades gubernamentales y el marco legal y reglamentario en el que se desarrolla la vida de la ciudad; y la económica, compuesta por las características que determinan los diferenciales de la estructura económica de base, el perfil de desarrollo local y el potencial de inserción a la economía global.

Por último, un ranking muy relevante es el que construye Mercer (MHRC), el que si bien no tiene por objetivo directo medir la competitividad de las ciudades sino la calidad de vida en ellas, cobra importancia dado que cada vez con mayor fuerza es utilizado por las empresas -e incluso por los paísespara determinar sus proyectos de inversión transnacionales. Este ranking se construye en función del costo de vivir en cada ciudad, para lo que ha agrupado una serie compleja de indicadores en cua-

Figura 1. Ranking 2004 de las mejores ciudades para hacer negocios en Latinoamérica, en base a datos de América Economía.

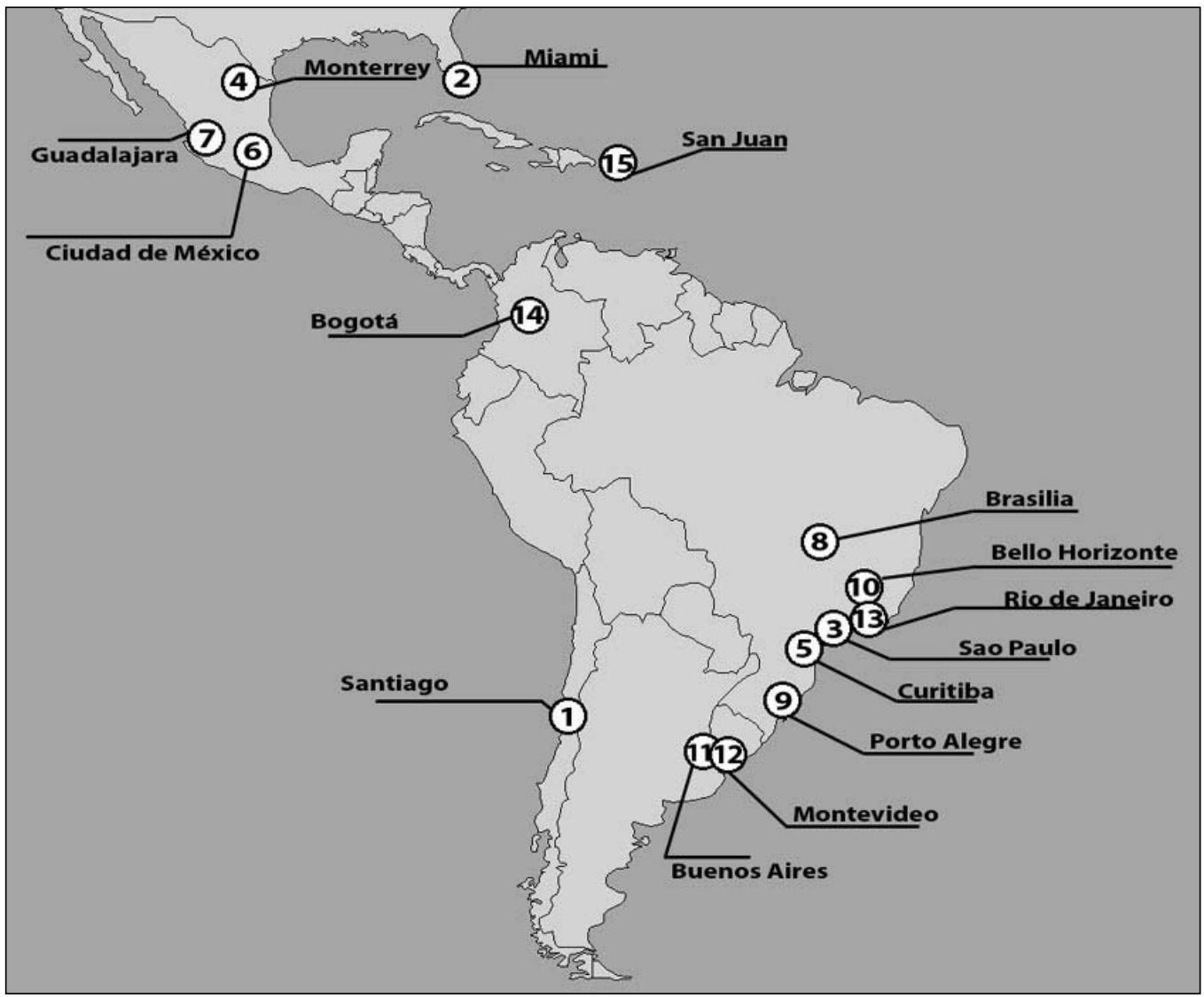


tro dimensiones: ambiente político y social, ambiente económico, ambiente socio-cultural y ambiente natural.

\section{Recapitulando: el caso de Santiago}

La ciudad de Santiago posee características que la convierten en un interesante caso de estudio para aplicar los conceptos discutidos hasta ahora. Esto porque Chile se erige, hoy y quién sabe por cuánto tiempo, como uno de los pilares económicos y políticos de la región, una especie de faro aparentemente incólume y autárquico ante el tornado de caos y desorden que despierta cíclicamente en el subcontinente. Esto no es casual, sino fruto de la reestructuración integral que experimentó el país en las décadas de los setenta y ochenta, de la relativamente pacífica transición a la democracia de los noventa, del continuismo de las políticas monetarias con que han funcionado los gobiernos concertacionistas, de la creciente credibilidad que han ido ganando buena parte de las instituciones públicas, del relativo apego a la palabra escrita que posee el carácter chileno, y del proceso que ha ido diferenciando de manera exitosa a los distintos subsistemas de la vida social (político, judicial, económico, artístico, educacional).

\section{1. ¿Compite Santiago o compite Chile?}

Santiago, como capital del país, se ha visto en extremo beneficiada por estos procesos. La opinión de Felipe Abarca (2003), de América Economía, refuerza esta idea, ya que para él Santiago no es competitiva tanto por sus logros a nivel metropolitano ni a nivel de sus gobiernos locales, sino más que nada porque tributa del éxito económico y de la imagen que se ha forjado el país a nivel internacional. Esto se revela en proyectos como la "Marca Chile" o "Chile: país plataforma”, los cuales se encuentran enfocados a promocionar "las condiciones que ofrece el país a los capitales privados foráneos" (De Mattos et al., 2004) y a favorecer el territorio nacional, pero sus frutos se han concentrado más que nada en un aumento de la atractividad de Santiago.

Las reformas regionalizadoras que desde los setenta se han aplicado en la legislación nacional han corrido una suerte parecida. Bajo la idea de descentralizar los recursos y la toma de decisiones de mane- ra tal que no pueda hablarse política, administrativa, económica y simbólicamente de un país que se reduce a su ciudad capital, y apoyado por estudios de CORFO, ODEPLÁN y CONARA que promovían un sistema político-administrativo más adecuado con la realidad del país, en 1975 se decidió dividir el territorio nacional en 13 regiones. Los efectos de dichas medidas, sin embargo, distaron mucho de las esperadas. Santiago sigue concentrando buena parte de las inversiones que llegan al país, y en él se siguen localizando los headquarters que comandan la economía nacional. De hecho, de las cincuenta empresas más importantes del país sólo dos, portuarias ambas, no tienen sus casas centrales en Santiago (Parnreiter et al., 2004).

El fracaso de la descentralización queda en evidencia también con el caso de Valparaíso, ciudad capital de la Quinta Región. Ella se vio en apariencia y discurso beneficiada por los programas de desconcentración, ya que en 1990 se convirtió en sede del poder legislativo del Estado. Hoy, quince años después, se están levantando con creciente fuerza voces que solicitan el traslado del Congreso a su sede anterior, no sólo porque se ha vuelto un edificio vacío y disfuncional, ya que muchos de los diputados y senadores viajan a la Quinta Región sólo para asistir a las sesiones parlamentarias, las que se efectúan únicamente los días miércoles y jueves durante un par de meses al año; sino también porque el monumental edificio que se construyó para albergar al Congreso Nacional se insertó en la trama urbana de una manera que niega por completo la naturaleza misma de una ciudad declarada Patrimonio de la Humanidad por la UNESCO. Los ciudadanos perciben el edificio del Congreso no como un símbolo de igualdad regional sino como la expresión misma de un poder que desde la capital se prolonga para controlarlo todo, una especie de brazo cuyo puño se materializa, cerrado y amenazador, en el monumental edificio construido.

Para cerrar este punto cabe señalar que, tal como se ha venido argumentando, la importancia central de Santiago en el contexto nacional no es sólo fruto de fracasadas reformas descentralizadoras sino, más importante aún, de un cambio de escenario donde la capital ya no compite con el resto de las ciudades del territorio nacional, sino que ha entrado en competencia con otras ciudades que poseen el mismo 
nivel de atractividad y competitividad que ella a nivel internacional. Estas ciudades serían, para GaWC, aquellas que comparten el nivel de mundialidad que posee Santiago. De las 55 ciudades clasificadas por GaWC como "ciudades globales", 35 comparten la calidad santiaguina de "ciudad gamma", entre ellas Barcelona, Beijing, Ámsterdam y Miami. Teniendo eso en mente, y como bien precisa De Mattos (2004), privilegiar la descentralización de Santiago no implicaría de ninguna manera un reforzamiento de las regiones chilenas, sino que el beneficio se trasladaría hacia el resto de las ciudades gammas repartidas por el globo.

\subsection{Competitividad vs. calidad de vida}

Los buenos rankings que presenta la ciudad en términos de competitividad han sido acompañados por datos muy auspiciosos en otras líneas. En cuanto a su calidad de vida, MHRC (Mercer) calificó durante 2003 a Santiago en el lugar 79 a nivel mundial, y en tercer lugar a nivel latinoamericano, sólo por debajo de Montevideo y Buenos Aires. Esto constituye una buena posición, ya que Santiago es una de las pocas ciudades del ranking que posee una población que supera los cuatro millones de habitantes, una variable naturalmente asignada como perjudicante de la calidad de vida ${ }^{19}$. Los factores peor evaluados de la ciudad son los riesgos geofísicos, la delincuencia -pese a que América Economía destaca este ítem como una de sus fortalezas-, la contaminación ambiental, la congestión del tráfico y el transporte urbano. En cuanto a su Desarrollo Humano, el informe confeccionado el año $2001^{20}$ por el PNUD evaluó a Chile en lugar 39 de 162 países, lo que nuevamente le otorga a Santiago ventajas relevantes por ser la capital nacional. Financieramente, por su parte, la revista América Economía ha venido evaluando positivamente a Santiago durante los últimos años, siendo elegida en 2004 como la mejor ciudad para hacer negocios de Latinoamérica.

\footnotetext{
${ }^{19}$ Van den Berg y Braun (1999) señalan que "con la congestión vehicular, el envejecer de distritos urbanos y otros problemas, ciudades grandes se encuentran cada vez en mayor desventaja ante ciudades de tamaño medio" (traducción propia).

${ }^{20}$ Para Chile se utilizaron datos de 1996, anteriores a la crisis económica que golpeó fuertemente el país.
}

Estas buenas posiciones en los rankings internacionales, sin embargo, debe tratarse con algo de cuidado. Porque así como pueden levantarse legítimas dudas acerca de si es toda la ciudad la que compite o sólo algunas piezas de ella, así también uno puede poner en duda si los índices de calidad de vida realmente reflejan la condición de vida de todos los habitantes de la ciudad. La respuesta quizás se dirija a complementar los anteriores análisis con el coeficiente Gini que construye Naciones Unidas, y que dice relación con la inequidad de los países. El índice opera midiendo cuánto se distancian los hogares de la perfecta distribución equitativa; así, un país que obtenga un cero tendrá sus ingresos perfectamente distribuidos, mientras que un país con 100 posee una poco envidiable inequidad perfecta. En 2003, de un total de 111 países, Chile se situó en el lugar 104 con un índice de 57,5, lo que lo deja debajo de países como Rwanda (17), Pakistán (27), Uruguay (76) y Ecuador (84), todos los cuales presentaron índices de desarrollo humano y de calidad de vida significativamente menores a los de Chile.

Bajo estos datos da la impresión que Chile, y con él Santiago, funcionan bajo una fiebre competitiva que es capaz de arrasarlo todo con tal de aparecer atractivo ante el mercado internacional y exitoso ante el resto de los países latinoamericanos. Un buen ejemplo de esto es lo que ocurre actualmente en el centro de la capital con el fenómeno de la gentrificación. El gobierno metropolitano, junto a las municipalidades pericentrales, diseñaron a fines de los noventa un plan de repoblamiento que no sólo tenía como objetivo reactivar el deteriorado centro de la ciudad, sino especialmente la construcción de una imagenciudad segura, activa, competitiva y moderna. Quiéraselo o no, son los centros históricos los que guardan con mayor fuerza las claves del imaginario de toda ciudad, y por tanto volverlos atractivos es una especie de requisito para participar del mercado mundial. Sin embargo, el asunto se vuelve paradójico toda vez que al intentar reactivarlos se les destruye, como bien ha estudiado Rojas (1999). En Santiago este proceso fue radical, ya que no sólo se arrasó con buena parte del patrimonio de los barrios intervenidos, los que se vieron súbitamente asediados por condominios en altura y lofts, sino que además se produjo una fuerte expulsión de sus habitantes de bajos ingresos hacia sectores periféricos de la ciudad. En el barrio Brasil, por ejemplo, una buena propor- 
ción de los cités que daban vida a la zona fueron erradicados o demolidos para construir edificios de viviendas (Pinto, 2002). La gentrificación, por tanto, nos advierte con claridad lo que puede producir la fiebre por la competencia -del país antes que de la ciudad, en este caso-, donde en tanto se aumente la atractividad de la ciudad no importa pasar por encima del patrimonio urbano y de los grupos sociales más desprotegidos, enviándolos a aquellos barrios que permanecen invisibles y ajenos a las cámaras y a las postales.

\subsection{Las carencias de la ciudad}

Santiago es, entonces, una especie de ilusión, un espejismo que se presenta al mundo como competitivo, eficiente, moderno y productivo, pero que en su realidad material no posee los recursos específicos suficientes para soportar su imagen. Esto se agrava, además, con respecto a dos factores hoy por hoy significativos: la falta de una imagen o espíritu urbano distinguible, y la inexistencia de un proyecto de ciudad. El primero dice referencia con que la capital de Chile posee una imagen, no sólo en Latinoamérica sino especialmente en los santiaguinos, de una ciudad que "no tiene alma"21, como paradójicamente señaló el ex-Intendente de la ciudad Marcelo Trivelli (citado en Abarca, 2003). Su identidad es débil, y las imágenes que se comunican de ella -a través del cine, los discursos, las postales, la literatura, la publicidad, del sentir de la ciudad- no poseen la magia que distingue a ciudades como $\mathrm{Pa}$ rís, Nueva York, Tokio, Río de Janeiro o Buenos Aires. Abarca (2003) lo explica bajo la idea de que "es el síndrome de la ciudad capital de un país pequeño, donde se habla del país, pero pocos hablan de la ciudad y de sus problemas, ya que muchos identifican a la primera con la segunda”.

La segunda carencia, la falta de un proyecto de ciudad, se exacerba toda vez que Santiago no posee

${ }^{21}$ Para una imagen bien lograda de cómo, pese a las múltiples y variadas transformaciones que puede sufrir una ciudad, hay algo que permanece, véase el film "Perdidos en Tokio", de Sofia Coppola.

Figura 2. Uno de los subcentros financieros más activos de Santiago ha sido llamado Sanhattan, con la intención evidente de aprovecharse de las ideas de modernidad y desarrollo con que se asocia a Manhattan. Sin embargo, y tal como esta fotografía parece proponer, uno puede seriamente preguntarse si la imagen que se intenta construir no es más que una gran escenografía fácilmente desmontable.

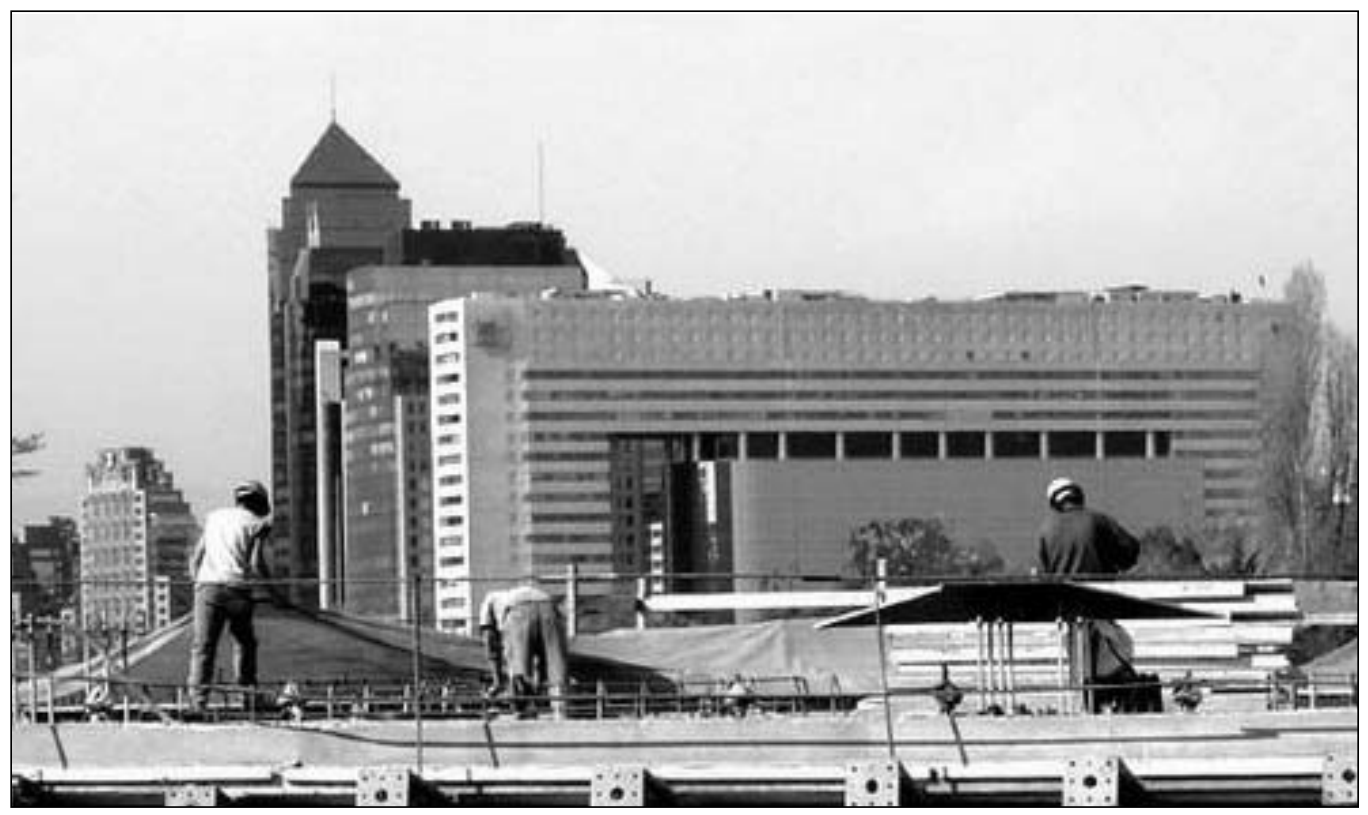

Fuente: Juan Pablo Arias. 
un gobierno metropolitano que conduzca el desarrollo, armonizando las características y necesidades de sus más de 30 gobiernos locales. Tomando un caso extranjero como referente, en Londres se reestableció hace poco el Gobierno Metropolitano del Gran Londres, un órgano autónomo y democrático que resurge bajo la idea de "unificar el desarrollo de la ciudad a través de la elaboración de una serie de planes estratégicos de desarrollo urbano (desarrollo espacial, económico, cultural, medio ambiente, transporte, vivienda, etc.)" (Czischke, 2004). Dada las múltiples y poderosas fuerzas que actúan en toda ciudad competitiva se hace necesaria e imprescindible la existencia de gobiernos metropolitanos que posean una visión de ciudad y que, con legitimidad normativa y ciudadana, fuerza política y recursos financieros, sean capaces de defender dicha visión ante las presiones que provengan de grupos económicos, empresas inmobiliarias y transnacionales, gobiernos locales y otros grupos sociales interesados en materias urbanas. Precisamente, sobre el caso de Londres, Czischke (2004) señala que "una característica importante de este nuevo modelo de gobierno de la ciudad, es el hecho de estar fuertemente basado en la persona del alcalde (the Mayor of London), quien ha jugado un rol protagónico por sus frecuentes choques con la autoridad central".

Quizás el mayor beneficio de tener un gobierno metropolitano se relaciona con construir una institución que se preocupe por la ciudad de manera integral, entendiéndola como un organismo complejo, compuesto de múltiples realidades que se superponen. Esto es relevante porque, en orden de mejorar su atractividad, los gobiernos -a cualquier escala- usualmente se esfuerzan por mejorar aquellas variables en las que resultan peor evaluados, en general sin tener en consideración que al realizar cualquier modificación, por mínima que esta sea, es el sistema completo el que se ve afectado. Tomemos por ejemplo el ranking de calidad de vida que elabora Mercer. En él, las mayores debilidades de Santiago son la congestión y el transporte urbano. Para mejorar estas falencias se han invertido ingentes sumas de dinero, tanto en la construcción y ampliación del Metro como en la subvención de autopistas urbanas. Estas obras se pretenden justificar precisamente bajo el paraguas del crecimiento, la competitividad y, en última instancia, de la calidad de vida: "No me cabe duda que estas (obras de infraestructura vial urbana) van a traer enormes beneficios para la calidad de vida de nuestros habitantes", señalaba hace poco con dudosa ingenuidad el expresidente de la Cámara Chilena de la Construcción (Echeverría, 2004). Su declaración sin embargo, obvia de manera radical, borrándolas de un plumazo, las consecuencias perversas que genera todo proyecto urbano. Así, por la falta de una visión integral y bajo el objetivo de mejorar los indicadores de transporte en una ciudad congestionada, se pueden fácilmente producir empeoramientos en los indicadores de otros factores, empeorando así la calidad de vida. Para el caso de las autopistas urbanas, por ejemplo, un efecto no deseado podría ser que con ellas se potencia la expansión de la ciudad, con todos los costos y problemas que ello implica; así, cuando se señala que las autopistas acortarán los tiempos de viaje en el periurbano, no se está teniendo en consideración que las mismas autopistas probablemente producirán una expansión de la mancha urbana más allá de sus límites actuales, y no precisamente la compresión relativa de los tiempos de viaje dentro de la capital. Por otra parte, si el mercado de trabajo de una ciudad produce viajes en exceso a lo largo y ancho de ella, entonces los cientos de millones de dólares y la legislación vigente quizás no debieran invertirse en mejorar la infraestructura, sino en reducir los patrones de segregación residencial que operan aún a gran escala en Santiago (Sabatini et al., 2001). Por último, y cambiando levemente el rumbo de los dardos, pueden también criticarse los efectos que producen las autopistas urbanas, pero ya no a nivel de costos ni tiempos de viaje, sino en tanto degradan la cultura y la vida urbana. Como bien señala Sennett (1994), "en la medida que las carreteras se han hecho más rectas y uniformes, el viajero cada vez tiene que preocuparse menos de la gente y de los edificios de la calle para moverse, realizando movimientos mínimos en un entorno que cada vez resulta menos complejo [...] El espacio se ha convertido así en un medio para el fin del movimiento puro: ahora clasificamos los espacios urbanos en función de lo fácil que sea atravesarlos o salir de ellos". Dentro de las muchas ciudades que podemos construir, y seguramente todas ellas coexisten bajo distintas proporciones, la pregunta es cuál de ellas vamos a privilegiar: la ciudad de la velocidad o la del encuentro. 


\section{Conclusiones}

Las raíces de la gestión moderna de las ciudades -la manera en que actualmente se regulan y conducen los procesos urbanos, y el modo en que se administran, financian y venden las ciudades- deben rastrearse al menos doscientos años en el tiempo. Al despuntar el siglo XIX, el mundo occidental se vio abordado por procesos racionalizadores que lo atravesaron por completo. Con ello, la manera de vivir, pensar y soñar las ciudades se puso en sintonía con un intento desesperado por imponer o rastrear un orden detrás del caos. Con la razón en una mano y un buldózer en la otra, muchas ciudades a lo largo del mundo se vieron transformadas para "dejar entrar la luz" y erradicar de esa manera los vicios que parecían caracterizarlas. El Estado se levantó como un ente mesiánico, una entidad todopoderosa que se creyó capaz y responsable de conducir hasta la más mínima variable de la vida social.

La complejidad de la realidad, sin embargo, se mostró inabordable en toda su extensión. El desencanto, la inoperancia y la frustración se acumularon hasta terminar por fracturar el modelo. El Estado fue desmantelado y su protagonismo se redujo a una vigilancia lejana al nuevo y desarticulado actor que comenzaba a hacerse cargo de guiar los procesos sociales, el Mercado. La premisa rectora era que la óptima distribución de los recursos económicos, dada de manera natural por las leyes del propio mercado, desanudaría por sí sola las malignidades que se desenvuelven en el resto de los subsistemas sociales.

En este escenario destaca también el privilegiado sitial al cual las ciudades fueron alzadas. Fruto de la informalización de los procesos sociales, del crecimiento endógeno, de la retracción del Estado, de la escasez de recursos y de la multiplicidad de necesidades, los gobiernos territoriales -locales, comunales, metropolitanos- se vieron obligados a competir por recursos escasos para proyectos y necesidades que eran innumerables. La competitividad dejaba de ser una opción para convertirse en una necesidad. La resolución de este concepto, sin embargo, dista mucho de ser simple. La afirmación misma de que las ciudades compiten ha sido puesta en duda, habiendo quienes aseguran que ellas sólo son el locus o territorio donde se localizan las empresas, las reales competidoras. Otra posición, más tradicional, señala que no son las ciudades las que atraen recursos sino los territorios nacionales. Para el caso de Santiago, por ejemplo, autores como Abarca (1996) y Fuentes y Sierralta (2004) afirman que la atractividad de la capital proviene sólo de su condición central en un "país global". Como vemos, el foco se ha trasladado desde las empresas que se localizan en una ciudad al país donde se localiza la ciudad.

En este nuevo escenario, donde cada dólar debe ser ganado con sudor y sangre, toda herramienta que pueda mejorar la competitividad de un territorio es más que bienvenida. Una de las más particulares del último tiempo es el fenómeno del marketing urbano. Es cierto que este instrumento profesional destinado a vender los territorios ha sido utilizado desde tiempos inmemoriales para atraer personas y recursos, pero es sólo desde la era contemporánea que la imagen de una ciudad se ha instrumentalizado tan masiva y racionalmente.

Quiero terminar este largo recorrido señalando que, en tiempos donde la competitividad parece serlo todo, es fácil perder de vista lo que debiera ser el foco fundamental de una estrategia de desarrollo urbano: producir mejoras crecientes en la calidad de vida de los habitantes de las ciudades. La competitividad y el marketing urbanos no deben plantearse nunca como fines-Begg (1999) llega a hablar incluso de un ethos competitivo-, sino ante todo como herramientas o medios para alcanzar ciudades más amables, para hacer de los territorios urbanos lugares más vivibles. Por lo mismo, debe tenerse siempre en cuenta que no toda inversión es una buena inversión.

\section{Referencias bibliográficas}

Abarca, F. (2003). "La hora del marketing”. América Economía. www.americaeconomia.com/ FilesMC/ciudadessp-03.pdf

Albuquerque, F. (1995). "Competitividad internacional, estrategia empresarial y el papel de las regiones". EURE Revista Latinoamericana de Estudios Urbano Regionales, 21, 63: 41-56.

Begg, L. (1999). "Cities and competitiveness". Urban Studies, 5/6, 36: 795-809.

Borja, J. y M. Castells (1997). Local y global. La gestión de las ciudades en la era de la información. Barcelona: Taurus. 
Brenner, N. (2003). "La formación de la ciudad global y el re-escalamiento del espacio del Estado en la Europa Occidental Post-Fordista". EURE Revista Latinoamericana de Estudios Urbano Regionales, 29, 86: 5-35.

Cabrero, E., I. Orihuela y A. Ziccardi (2003). Ciudades competitivas, ciudades cooperativas: Conceptos claves y construcción de un indice para ciudades mexicanas. México: CIDE.

Castells, M. (1987). "El nuevo modelo mundial de desarrollo capitalista y el proyecto socialista". Guerra, A. (ed.), Nuevos horizontes teóricos para el socialismo. Madrid: Sistema.

Choay, F. (1976). El urbanismo, utopias y realidades. Barcelona: Lumen.

Conesa, J.C. (2005). “Teoría económica del capital y la renta”. www.econ.upf.es/-conesa/libro/ book.html.

Considerant, V. (1979). Description du Phalanstère et considerations sociales sur l'architectonique. Paris: G. Durier

Czischke, D. (2004). "La ciudad de la tercera vía". La red de La Segunda.com, www.lasegunda.com/ _portada/La_Red/darinka/index.asp

De Certeau, M. (1984). The practice of everyday life. Berkeley: University of California Press.

Dematteis, G. (1998/99). "Nom basta una forte identità. La città vive solo se è un "nodo". Telèma, 15. www.fub.it/telema.

De Mattos, C. (2004). De la Planificación a la Governance: implicancias para la gestión urbanoregional. Notas de clase.

De Mattos, C., L. Fuentes y C. Sierralta (2004). Santiago, ¿ciudad de clase mundial? Santiago: EureLibros.

Echeverría, F. (2004). "Autopistas urbanas y calidad de vida”. Diario El Mercurio, Cuerpo A, p. 2, 25 de julio.

Fuentes. L. y C. Sierralta (2004). "Santiago de Chile, ¿ejemplo de una reestructuración capitalista global?" EURE Revista Latinoamericana de Estudios Urbano Regionales, 30, 91: 7-28.

Foucault, M. (1992). Microfisica del poder. Barcelona: La Piqueta.

Giddens, A. (1993). Consecuencias de la modernidad. Madrid: Alianza.

Gilly, J.P. y A. Torre (eds) (2000). Dynamiques de proximité. Paris: L'Harmattan.
Grimberg, C. (1985). Historia universal. Santiago: Ercilla.

Krugman, P. (1996). The self-organizing economy. Oxford: Basil Blackwell.

Leibniz, G. (1982). Discurso de metafisica. Madrid: Alianza.

Lever, W.F. (1999). "Competitive cities in Europe". Urban Studies, 5/6, 36: 1029-1044.

OECD (1997). Industrial competitiveness. Paris: OECD.

Owen, R. (1993). "The book of the new moral world". Selected works of Robert Owen, vol. 3. London: William Pickering.

Parnreiter, C., K. Fischer y K. Imhof (2004). “The missing link between global commodity chains and global cities: the financial sector in Mexico City and Santiago de Chile". GaWC Research Bulletin, 156. www.lboro.ac.uk/gawc/rb/ rb156.html.

Pinto, C. (2002). Pobreza encubierta en las viviendas colectivas de la zona centro de Santiago. Ventajas y desventajas socioeconómicas y urbanas. Santiago: Taller de Titulación en Política Urbanas, Pontificia Universidad Católica de Chile.

Platón (1992). Diálogos, Filebo, Timeo, Critias. Madrid: Gredos.

Porter, M. (1990). The competitive advantage of the inner city. New York: The Free Press.

(1998). The competitive advantage of nations. London: Macmillian.

Rama, A. (2004). La ciudad letrada. Santiago: Tajamar.

Rodrigues, J.N (2001). "Entrevista a Paul Romer: 'El cambio ocurrió en nuestra cabeza'". www.mujeresdeempresa.com/ebusiness/ ebusiness010501.shtml.

Rodríguez, A., F. Moulaert y E. Swyngedouw (2001). "Nuevas políticas urbanas para la revitalización de las ciudades en Europa”. Ciudady Territorio. Estudios Territoriales, 33, 129: 409-424.

Rojas, E. (1999). Old cities, new assets. Washington, D.C: BID.

Sabatini, F. (2000). "Reforma de los mercados de suelo en Santiago, Chile: efectos sobre los precios de la tierra y la segregación residencial". EURE Revista Latinoamericana de Estudios Urbano Regionales, 26, 77: 49-80. 
Sabatini, F., G. Cáceres y J. Cerda (2001). "Segregación residencial en las principales ciudades chilenas: tendencias de las tres últimas décadas y posibles cursos de acción”. EURE Revista Latinoamericana de Estudios Urbano Regionales, 27, 82: 21-42.

Sachs, J. y J. McArthur (2001). "The Growth Competitiveness Index: Measuring technological advancement and the stages of development". Global Competitiveness. New York: Oxford University Press.

Sanders, J. (2003). Celluloid skyline. New York and the movies. New York: Knopf.

Sassen, S. (1991). The global city. New York, London, Tokyo. Priceton: Princeton University Press.

Sennett, R. (1994). Carne y piedra. Madrid: Alianza.

Simmel, G. (2005). "La metrópolis y la vida mental". Bifurcaciones, Revista de Estudios Culturales Urbanos, 4. www.bifurcaciones.cl/004/ reserva.htm.

Sobrino, J. (1999). "Competitividad Industrial y Finanzas Públicas Municipales en las principales ciudades del país". Ponencia presentada en el Primer Congreso de gobiernos locales, el futuro politico de México. Guadalajara: IGLOM. http:// iglom.iteso.mx/sobrino.pdf.

Torres, A. (1996). "Imaginacao e metropole: as ofertas paradigmáticas do Rio de Janeiro e de Sao Paulo”. Machado, P.y M. de Vasconcellos (orgs.),
Cidade e imaginacao. Rio de Janeiro: PROURN/ FAU-UFRJ.

Trujeque, J.A. (2000). “Ciudades rotas. La experiencia de la globalización en ciudades de la frontera noreste de México". Cuadernos del Cendes, 17, 43: 1-28.

Vainer, C.B. (2000). "Patria, empresa y mercadoría. Notas sobre a estrategia discursiva do Planejamento Estratégico Urbano". En Arantes, O., C. Vainer y E. Maricato (eds.), A cidade do pensamento único. Desmanchando consensos. Petrópolis: Editora Vozes.

Van den Berg, L. y E. Braun (1999). "Urban competitiveness, marketing and the need for organising capacity”. Urban Studies, 5/6, 36: 987-999.

Veltz, P. (1996). Mundialización, ciudades y territorios. La economía de archipiélago. Barcelona: Ariel.

Vicuña Mackenna, B. (1872). La transformación de Santiago. Notas e indicaciones a la Ilustre Municipalidad, al Supremo Gobierno y al Congreso Nacional. Santiago: Imprenta de la Librería El Mercurio.

Webster, D. y L. Muller (2000). Urban competitiveness assesment in developing country urban regions: the road forward. Washington, D.C.: Urban Group, INFUD-WB.

Wirth, L. (2005). "El urbanismo como modo de vida”. Bifurcaciones Revista de Estudios Culturales Urbanos, 2. www.bifurcaciones.cl/002/ reserva.htm. 